\title{
LA MEDICINA INDÍGENA EN LA ESPAÑOLA Y SU COMERCIALIZACIÓN (1492-1550)
}

\author{
Esteban Mira Caballos \\ Doctor en Historia de América por la Universidad de Sevilla - Miembro del grupo de investigación \\ “Andalucía y América: tierra y sociedad" del Depto. de Historia de América de la Universidad de Sevilla.
}

\section{RESUMEN}

En este artículo destacamos los importantes conocimientos herborísticos que llegaron a poseer los curanderos o behiques indígenas de la Española. Estos ocultaron a los españoles sus conocimientos, por un lado, como medio de conservar su situación social privilegiada, y, por el otro, como otra forma de rechazo hacia el grupo conquistador.

Los españoles pronto se percataron de la importancia que tenía la herborística indígena como empresa económica comercializando con España numerosos licores y plantas medicinales.

\section{SUMMARY}

In this article the important herbalist knowledge that the native healers or behiques possessed in la Española are pointed out. They concealed their herbalist knowledge as a means to preserve their priviledged social status, on the ather haud, es a rejection to the conquerors.

Soon the spaniards realised the importance that the native herbalist knouledge had as an enterprise and began a profitable trade of liqueur and medicinal plants to the Iberian Peninsula.

\section{INTRODUCCIÓN.}

A la llegada de los europeos a las Antillas Mayores se encontraron con unos aborígenes que, pese a vivir en un estadío muy atrasado de civilización, estaban perfectamente adaptados a su hábitat natural. Evidentemente, conocían su medio natural, con el que coexistían en perfecta armonía, y sabían los remedios fundamentales para el tratamiento de aquellas enfermedades que de manera más común les afectaban.

No cabe duda que en los primeros tiempos debieron rivalizar los barberos y los cirujanos españoles con los behiques indígenas, pues no debemos olvidar que en el período estudiado por nosotros la infraestructura médica española era extremadamente precaria. A la Española llegaron en los primeros años numerosos sanitarios que tenían dificultades para practicar la medicina en la Península, bien debido a carecer de título, o bien por pertenecer a alguna minoría étnica. No en vano ya en el 


\section{ESTEBAN MIRA CABALLOS}

propio siglo XVI el cronista Gonzalo Fernández de Oviedo advirtió que la mayoría de los médicos y cirujanos que arribaban a Santo Domingo olvidaban sus títulos acaso "porque nunca los tuvieran"1.

Igualmente, la infraestructura hospitalaria en esta época fue francamente insuficiente para cubrir las necesidades de los españoles que, como bien se decía en la época, llegaban bastante "dolientes" a esta isla, tras varias semanas de travesía ultramarina.

A estas deficiencias tanto de personal suficientemente formado como de instalaciones hospitalarias habría que unir la existencia de enfermedades desconocidas hasta entonces por los sanitarios españoles y que, en un primer momento, constituyeron un hándicap difícil de superar.

De ahí que en las primeras décadas encontremos numerosas licencias reales autorizando el retorno de algunos españoles a Castilla para curarse de sus enfermedades ${ }^{2}$. En estos documentos se señalaban como causas de las dolencias "la naturaleza" y el clima de la isla, pues no en vano los padecimientos más habituales eran fiebres y otras patologías tropicales, desconocidas hasta entonces por el grupo conquistador.

Hasta tal punto se mostró inoperante la medicina española en las primeras décadas que los indios, pese a la existencia de hospitales tanto para españoles como para negros e indios, preferían ponerse en manos de sus tradicionales behiques ${ }^{3}$.

Así, cuando en 1509 un indio, llamado Francisquito, fue azotado por su encomendero Francisco de Solís, después de atenderlo en primera instancia los propios españoles, otros indios se lo llevaron al bohío del Capitán "para que lo curasen mejor"4. A no dudarlo, los indios continuaron practicando su medicina tradicional en la

1 MiRa CABAllos, E. (1994): "Sanidad e instituciones hospitalarias en las Antillas (1492-1550)", Asclepio, Revista de Historia de la Medicina y de la Ciencia, Vol XLVI, fasc. 2, Madrid, p. 184.

2 Por ejemplo en 1511 fue autorizado el escribano mayor de minas de la Española, Juan de Serralonga para ir a Castilla a curarse de sus enfermedades. Real Cédula a Diego Colón, Sevilla, 21 de junio de 1511. AGI, Indiferente General 418, L. 3, ff. 113-113v. Asimismo fueron autorizados en 1514 el tesorero Miguel de Pasamonte, en 1525 a un vecino de la isla llamado Gómez García, y en 1538 a la mujer de Melchor de Torres "para curarse de una enfermedad contagiosa". Real Cédula a Miguel de Pasamonte, León, 28 de noviembre de 1514. AGI, Indiferente General 419, L. 5, ff. 120-121. Real Cédula a Gómez García, 15 de julio de 1525. AGI, Indiferente General 420, L. 10, ff. 19v-20. Real Cédula al presidente y oidores de la Audiencia de Santo Domingo, Toledo, 20 de diciembre de 1538. AGI, Santo Domingo 868, L. 1, ff. 153-154.

3 Ya en las instrucciones otorgadas al gobernador Ovando en 1503 se le ordenó que hiciese hospitales "en que se acojan y curen los pobres, así de los cristianos como de los indios...". Instrucciones a frey Nicolás de Ovando, Zaragoza, 29 de marzo de 1503. AGI, Indiferente 418, L. 1, ff. 94v-98. CoDOIN, Serie $1^{a}$, T. 31, pp. 158-174. KONETZKE, R. (1953): Colección de documentos para la historia de la formación social en Hispanoamérica, 1493-1810. Madrid, C.S.I.C., pp. 9-13.

4 Mira Caballos, E. (1993): "El pleito de Diego Colón- Francisco de Solís: el primer proceso por malos tratos a los indios en La Española (1509)", Anuario de Estudios Americanos, T. L, Núm. 2, Sevilla p. 326. El indio, que llegó agonizante al bohío indígena, murió a los pocos días; sin embargo, la intención 
intimidad de sus casas o bohíos y, como veremos a continuación, al margen de la ciencia médica española.

\section{EL BEHIQUE Y LOS CONOCIMIENTOS MEDICOS INDIGENAS}

Por desgracia los españoles tan sólo llegaron a conocer algunos de los conocimientos herborísticos que los indígenas de la Española poseían. No debemos olvidar que los aborígenes ocultaron desde un primer momento los remedios médicos como medio de persuadir a los españoles a abandonar su territorio y, en palabras de Pedro Mártir de Anglería, "abolir toda memoria de ellos"'. Para lograr este fin, habida cuenta de la superioridad española - por supuesto logística, no numérica-, llevaron a cabo una resistencia pasiva que se catalizó en alzamientos a los montes, destrucción de sus propios "conucos" y un mutismo premeditado sobre los remedios médicos para determinadas enfermedades subtropicales.

En relación a este último aspectos tenemos una referencia muy interesante de Joséph Peguero, que se hizo eco de un hecho ocurrido en esta isla varias décadas después de la llegada de los españoles. Concretamente relató que a un español desposado con una india le entró el mal de las bubas y ésta, para evitar que se la contagiase a sus hijos, le proporcionó unas hierbas curativas, advirtiéndole "que en cuanto me descubras, yo moriré y me matarán mis parientes, que no quieren que ustedes sepan el como se cura este mal por ver si mueren todos"6. Igualmente, los indios guardaron celosamente la pócima para sanar las heridas causadas por las flechas envenenadas que lanzaban los indios caribes y que tantos estragos causaron entre las huestes hispanas hasta 1540 , en que por fin se averiguó el remedio?.

Por tanto, queda claro que los aborígenes ocultaron de manera consciente sus conocimientos médicos a los españoles como un sistema más de oposición hacia ellos. Evidentemente eran los behiques indígenas, cuya sabiduría era fruto de la experiencia acumulada de generaciones pasadas, los mejores conocedores de las soluciones médicas a las patologías propias de la isla ${ }^{8}$.

\footnotetext{
de los indios de llevarlo con los suyos para intentar salvarlo in extremis es muy significativa de la fe que tenían en su medicina tradicional.

5 ANGleria, Pedro Mártir (1989): Décadas del Nuevo Mundo. Madrid, Ediciones Polifemo, p. 41

6 PEguero, J. (1975): Historia de la conquista de la isla Española de Santo Domingo, trasumptada el año de 1762, T. I, Santo Domingo, Museo de las Casas Reales, p. 140.

7 Así lo relata Fernández de Oviedo. FERNANDEZ DE OVIEDO, G. (1992): Historia general y natural de las Indias, Madrid, Editorial Atlas, T. I, Lib. VI, Cap. XLVIII, pp. 210-211.

8 Evidentemente sus remedios se limitaban a las enfermedades comunes de las islas no a las que los españoles trajeron de España, de las que, como muy bien escribió Peguero, "no conocían ni se sabían curar, y así murieron infinitos...". PEGUERO (1975): Op. Cit., T. I, p. 177.
} 
Además estaba claro que a estos chamanes o behiques no les convenía difundir sus métodos curativos, pues a la sazón ya durante sus ceremonias prehispánicas, pedían a la mayoría de los asistentes que se saliesen fuera mientras aplicaban a su paciente la medicación. Evidentemente su poder radicaba en la exclusividad de sus conocimientos que desde luego no estuvieron nunca dispuestos a compartir con el resto de los indígenas, ni muchísimo menos con los españoles.

Entrando ya en el análisis de algunas de las soluciones médicas empleadas por los aborígenes, debemos decir que nuestro conocimiento se limita a lo que escribieron los cronistas, especialmente Fernández de Oviedo, el cual, en su ya citada Historia General y Natural de las Indias, le dedicó varios capítulos.

Los behiques, buhitis o boicios son tres de los nombres que más frecuentemente utilizaron los cronistas para designar a los chamanes o hechiceros indígenas ${ }^{9}$. Estos formaban parte de la élite dirigente, y eran personas muy respetadas por toda la población, aunque desde luego subordinados al cacique ${ }^{10}$. En cualquier caso algunos de ellos, en función de sus méritos personales como sanadores, tuvieron una "grandísima autoridad" entre los demás miembros de su comunidad".

Por lo demás, aunque fueron acusados de farsantes por algunos cronistas como fray Bartolomé de las Casas, lo cierto es que tenían, como ya hemos afirmado, un amplio conocimiento de la medicina natural que les permitía solventar positivamente las heridas más comunes, las calenturas y las fracturas "envolviendo los miembros en yaguas mojadas"12. Evidentemente el prestigio de estos behiques sólo se afianzaría con reiterados éxitos médicos y con la confianza auténtica de los demás miembros de su comunidad ${ }^{13}$. Así, Pedro Mártir de Anglería afirmó, refiriéndose a los curanderos indios, lo siguiente:

\footnotetext{
"Las calenturas se las curan fácilmente con jugo de hierbas, y con igual facilidad las heridas con tal que sean curables. Tienen y conocen mucha clase de hierbas salutíferas... Y no
}

\footnotetext{
9 Nosotros vamos a utilizar el más difundido que es lógicamente el de behique. Véase TEJERA, E. (1951): Palabras indígenas de la isla de Santo Domingo. Ciudad Trujillo, Editora del Caribe, p. 73.

10 CASSA, R. (1992): Los indios de las Antillas. Madrid, Mapfre, p. 114.

11 BENZONI, Girolamo (1989): Historia del Nuevo Mundo. Madrid, Alianza Editorial, p. 149.

12 PINO Y DE LA VEGA, Mario del (1963): Apuntes para la historia de los hospitales en Cuba (15231899). La Habana, Ministerio de Salud Pública, p. 13. El padre Las Casas, refiriéndose a los indios de Tierra Firme, aunque aplicable a los taínos de las Antillas, afirma que eran muy aficionados a hacerse sangrías en lomos y pantorrillas. LAS CASAS, Bartolomé de las (1951): Historia de Indias. México, Fondo de Cultura Económica, T. II, Lib. I, Cap. CLXV, p. 122.

13 De hecho cuando el paciente moría y se demostraba haber habido negligencia por parte del behique éste era reprendido e incluso golpeado salvajemente. Véase, por ejemplo, DEIVE, C. E. (1989): "El chamanismo taíno", en La cultura taína. Madrid, Editorial Túrner, p. 85.
} 


\section{LA MEDICINA INDÍGENA EN LA ESPAÑOLA Y SU COMERCIALIZACIÓN (1492-1550)}

usan ningún otro género de medicinas, ni quieren más médico que a los viejos de experiencia o a los sacerdotes conocedores de las ocultas virtudes de las hierbas..."14.

Igualmente, Gonzalo Fernández de Oviedo pudo comprobar personalmente en la Española los grandes conocimientos de estos chamanes indígenas, tal y como podemos observar en el texto que exponemos a continuación:

"Estos, por la mayor parte, eran grandes herbolarios y tenían conocidas las propiedades de muchos árboles y plantas e hierbas; y como sanaban a muchos con tal arte, teníanlos en gran veneración y acatamiento como a Santos..."15

Efectivamente, aunque los behiques revestían todas sus sesiones curativas con un amplio ritual mágico-ceremonial en el que supuestamente intentaban extraer al enfermo su mal ${ }^{16}$, lo cierto es que sus éxitos médicos estaban fundamentados en dos sólidos pilares, a saber: primero, en sus ya mencionados conocimientos herborísticos - los cuales no eran privativos de los taínos de la Española, sino de la mayoría de las comunidades indígenas americanas ${ }^{17}$-, y segundo, en sus grandes dotes psicológicas perfectamente descritas por algunos cronistas. Así, según Anglería, una vez acabado el ritual y concluido asimismo el tratamiento, el behique "sale corriendo a la puerta, que está abierta, y abriendo las manos las sacude y persuade que ha quitado la enfermedad y que pronto quedará bueno el enfermo. Pero, acercándose por la espalda, le quita de la boca el pedacito de carne como un prestidigitador, y le grita al enfermo diciendo: Mira lo que habías comido sobre lo necesario, te pondrás bueno porque te lo he quitado"18. No cabe duda de que esta persuasión que ejercía el curan-

14 ANGLERIA (1989): Op. Cit., pp. 433-434.

15 Fernandez De Oviedo (1992): Op. Cit., T. I, Lib. V, Cap. I, p. 112. Por su parte José Peguero, un historiador del siglo XVIII se hizo eco de estas informaciones de Fernández de Oviedo y de Herrera al afirmar lo siguiente: "Eran los sacerdotes por la mayor parte muy herbolarios, y con el conocimiento que tenían de las virtudes de las hierbas medicinales, curaban las dolencias de los indios, y les hacían creer que estas curas eran milagros que ellos hacían con facultad que les habían dado sus dioses". PEGUERO (1975): Op. Cit., T. I, p. 112.

16 No vamos a insistir en los detalles del ritual ya que fue descrito a la perfección por el padre Las Casas, Fernandez de Oviedo, Antonio de Herrera y fray Ramón Pané. Una buena descripción, basada en los escritos de Pané, puede verse en CASSA, R. (1990): Los taínos de La Española. Santo Domingo, Editorial Búho, p. 178-179. También DEIVE (1989): Op. Cit., p. 82-83.

17 Por ejemplo, Motolinía, refiriéndose a los indígenas de Nueva España dijo, que "hay algunos de ellos de tanta experiencia, que muchas enfermedades viejas y graves, que han padecido los españoles largos días sin hallar remedio, estos indios las han sanado...". MOTOLINIA, fray Toribio de (1990): Historia de los indios de la Nueva España. México, Editorial Porrúa, T. II, Cap. VIII, p. 102.

18 El subrayado es nuestro. ANGLERIA (1989): Op. Cit., p. 83. 
dero indio sobre sus pacientes y sus familiares era muy beneficiosa para su rápida recuperación ${ }^{19}$.

Esta circunstancia, unida a la profunda fe que los indios tenían depositada en sus behiques, hacía que el éxito estuviese asegurado, al menos en los casos de las enfermedades más comunes. Habida cuenta de que el behique se debía consolidar por sus propios méritos, sólo de esta forma lograba un prestigio importante sobre el resto de la población. Incluso cuando se equivocaban, podían ser recriminados y duramente castigados por los familiares si se demostraba que había sido por negligencia. Sin embargo, todos los cronistas coinciden en que esta situación no era frecuente ya que les era fácil demostrar que el fallecimiento había sido fruto de la providencia divina. Incluso los propios indios cuando consideraban que la persona padecía una enfermedad que excedía los conocimientos curativos de los behiques lo llevaban directamente al monte con agua y comida y lo abandonaban ${ }^{20}$. No cabe duda de que los propios indígenas eran sabedores de las posibilidades reales de su medicina naturista, por lo que en situaciones extremas, ni ellos mismos confiaban en su curación.

Antes de proceder a la aplicación del tratamiento le hacían un sahumerio con la intención de adormecerlos. En este sentido Benzoní, tan agudo como siempre, afirmó que los behiques cuando "querían curar a algún enfermo, iban a visitarlo, le suministraban ese humo y cuando estaban bien aturdido(s) le hacían la mayor cura"21.

Entre las habilidades que más brillantemente solventaban estos behiques estaba el restañamiento de heridas, para lo cual conocían numerosas pócimas que se elaboraban con diferentes plantas. Uno de estos productos para remediar las heridas eran unos polvos extraídos de un árbol, común en la isla, llamado Yaruma y cuyos resultados describió Fernández de Oviedo con las siguientes palabras:

19 La influencia que tiene este factor psicológico es muy importante. Ya Nicolás Monardes, en el siglo XVI, refiriéndose a las enfermedades, recomendaba permanecer lejos de ellas, entre otras cosas porque "la imaginación es muy gran obradera en el cuerpo, y estando lejos no imaginará en ello ni adolecerá por imaginación...”. MONARDES, N. (1885): Sevillana medicina que trata el modo conservativo y curativo de los que habitan en la muy Insigne ciudad de Sevilla, la cual sirve y aprovecha para cualquier otro lugar de estos reinos. Sevilla, Imprenta de Enrique Rasco, p. 334.

20 Esta situación la describió el padre Las Casas con gran detalle como podemos observar en las líneas que reproducimos a continuación: "Que cuando les parece que el enfermo está cercano a la muerte, sus parientes más cercanos lo llevan en una hamaca al monte, y allí, colgada la hamaca de dos árboles, un día entero les hacen muchos bailes y cantos, y viniendo la noche, pónenle a la cabecera agua y de comer cuanto le podía bastar para tres o cuatro días, y déjanlo allí, vanse y nunca más lo visitan. Si el enfermo come y bebe de aquello y al cabo convalece y se vuelve a su casa, con grande alegría y ceremonias lo reciben; pero pocos deben ser los que escapan, pues nadie, después de puestos allí, los ayuda y visita...". LAS CASAS (1951): Op. Cit., T. II, Lib. I, Cap. CLXV, p. 122.

21 BENZONI (1989): Ob. Cit., p. 149. 


\title{
LA MEDICINA INDÍGENA EN LA ESPAÑOLA Y SU COMERCIALIZACIÓN (1492-1550)
}

\begin{abstract}
"Estimaban mucho los indios aquestos árboles y decían que eran buenos para curarse las llagas...Y dicen (los españoles) que es como un cáustico, y que majados los cogollos tiernos de las puntas de las ramas de este árbol, los han de poner sobre la llaga, y aunque sea vieja, le comen la carne mala, y la ponen en lo vivo y sano, y la sesenconan, y continuándolas la encueran y totalmente sanan la llaga..."22.
\end{abstract}

No era este el único sistema empleado por los taínos para sanar las heridas ya que, por ejemplo, Peguero cita una especie de palmera datilera, llama Tamarinda, cuya corteza se molía y el producto resultante se colocaba sobre las heridas dando unos excelentes resultados como cicatrizante ${ }^{23}$.

Igualmente curaban las diarreas, básicamente a base de dietas "porque — según el padre Las Casas- se están tres y cuatro días sin comer ni beber"24. Luego consumían la fruta del guayabo que, a decir de Peguero, era de muy buena digestión "y son buenas para el flujo del vientre, y restriñen cuando se comen no del todo maduras, que estén algo durillas, para que cese el flujo del vientre..."25.

Asimismo tenemos noticias de que los behiques de la Española sanaban fácilmente la enfermedad de bubas, que tan mortífera fue para los españoles antes de averiguarse el secreto de su tratamiento ${ }^{26}$. Los indios la remediaban cociendo el palo del guayacán y extrayendo su zumo con tal éxito que, a decir de Fernández de Oviedo, "entre los indios no es tan recia dolencia ni tan peligrosa como en España, y en las tierras frías" 27.

Finalmente, sabemos que los indios empleaban otras muchas plantas con cualidades medicinales, a saber: el bálsamo o guaconax - comercializada en la primera década del siglo XVI por los españoles - como cicatrizante de heridas y yagas, la semilla del manzanillo como purgante ${ }^{28}$, la grasa de la iguana para reducir hinchazones $^{29}$, el zumo del "hobo" para los problemas de estómago ${ }^{30}$, etc. Por desgracia, los

\footnotetext{
22 Fernandez DE Oviedo (1992): Op. Cit., T. I, Lib. VIII, Cap. X, p. 255 y ss. Para la curación de heridas también utilizaban los indios el Guaconax, del que extraían un licor que los españoles llamaron Bálsamo. Dado su interés lo trataremos más adelante en un epígrafe aparte.

23 Peguero (1975): Op. Cit., T. I, p. 257. Fernández de Oviedo cita otros sistemas utilizados por los indios para curar las llagas como un polvo que se hacía con las pepitas del mamey. FERNANDEZ DE OVIEDO (1992): Ob. Cit., T. I, Lib. VIII, Cap. XX, p. 260.

24 LAS CASAS (1951): Op. Cit., T. II, Lib. I, Cap. CLXV, p. 122.

25 PEgUero (1975): Op. Cit., T. I, p. 260.

26 Ibidem, T. I, pp. 75-76.

27 FERNANDEZ DE OVIEDO (1992): Op. Cit., T. II, Lib. X, Cap. II, p. 9.

28 Aunque Oviedo advierte de su peligro ya que "a algunas personas apenas les afecta y a otras les da muy fuerte". FERNANDEZ DE OVIEDO (1992): Op. Cit., T. II, Lib. X, Cap. IV, P. 14.

29 Ibidem, T. II, Lib. XII, Cap. VII, p. 35.

30 Fernández de Oviedo dice que esto lo aprendieron los españoles de los indios. Ibidem, T. I, Lib. VIII, Cap. VI, pp. 253 y ss.
} 
documentos callan tanto el procedimiento exacto para aplicar estas pócimas como otras muchas soluciones médicas utilizadas por los indígenas. Sin duda, una parte importante de la ciencia herborística taína desapareció con su cultura, muriendo los últimos behiques sin confesar los secretos de su oficio.

\section{LA COMERCIALIZACION DE FARMACOS INDIGENAS: EL CASO DEL BALSAMO}

Desde la llegada de los españoles al Nuevo Mundo se interesaron por las virtudes médicas de su naturaleza e intentaron extraer de las nuevas plantas americanas licores y elixires mágicos ${ }^{31}$. Numerosos oportunistas intentaron "inventar" medicinas para comercializarlas tanto en el Nuevo Mundo como en Castilla. A partir de la década de los veinte la Corona se preocupó bastante del envío de plantas medicinales a Castilla, no sólo con la esperanza de que fuera útil médicamente sino también por la posibilidad que existía de que resultase una empresa lucrativa ${ }^{32}$.

Empezaremos hablando del tabaco que, como es bien sabido, era utilizado por los aborígenes tanto en sus fiestas y areitos como médicamente por los behiques para adormecer a los pacientes. Lo consumían de dos modos básicamente, a saber: uno, en forma de polvos que aspiraban por la nariz, y otra, haciendo sahumerios hasta "emborracharse" 33 .

En un primer momento su consumo estuvo mal visto por la sociedad española, motivo por el cuál tan sólo lo usó la población de color ${ }^{34}$. No obstante, sabemos que en 1518 fray Ramón Pané envió unas semillas de tabaco a Castilla para el jardín de Carlos $\mathrm{V}^{35}$, aunque con un fin únicamente ornamental.

Sin embargo, pasadas algunas décadas se comenzó a introducir su consumo entre los españoles, aunque exclusivamente por las virtudes medicinales que erróneamente se le atribuían. En este sentido, no debemos olvidar que del tabaco se decía que remediaba los dolores de cabeza y que era además cicatrizante, purgante y expecto-

31 Mira Caballos (1994): Op. Cit., p. 186.

32 Ibidem, p. 186. La ilusión por estos elixires fue tal que en la década de los treinta se encontró en Cubagua un brote aceitoso -posiblemente petróleo- y se autorizó para utilizarse como medicamento. Incluso en 1536, la Corona pidió a las autoridades de Cubagua que enviasen muestras a Castilla de ese "aceite petróleo" para experimentar con él y analizar su utilidad. Real Cédula a los oficiales de Cubagua, Madrid,, 10 de diciembre de 1532. AGI, Santo Domingo 1121, L. 3, ff. 33v-34. Real Cédula a los oficiales de Cubagua, Valladolid, 3 de septiembre de 1536. AGI, Santo Domingo 1121, L. 3, f. 122.

33 Aunque existe mucha bibliografía al respecto puede verse la voz cohoba en TEJERA (1951): $O p$. Cit., p. 144 y ss.

34 BENZONI (1989): Op. Cit., p. 148.

35 Regueiro y GonZaleZ-BARRAS, A. M. (1982): "La flora americana en la España del siglo XVI", En América y la España del siglo XVI, T. II. Madrid, C.S.I.C., p. 214. 
rante ${ }^{36}$. El tabaco arraigó tanto en los hábitos de los españoles que fue una de las pocas plantas "medicinales" indígenas que en poco tiempo llegó a cultivarse en la propia Península ${ }^{37}$.

La importación de estas plantas medicinales de la Española fue aumentando con el paso de los años, hasta el punto de que ya en torno a 1530 se consumían grandes cantidades de palo de Guayacán en el hospital de las Bubas de Sevilla. Concretamente en julio de 1531, el Rey concedió cierta cantidad de maravedís a Juan de Miranda, administrador de este hospital, para que adquiriese ramas de este arbusto de la Española, pues había 80 enfermos que se estaban curando precisamente "con el agua del palo del guayacán"38.

Resulta muy llamativo que recetas médicas descubiertas por los españoles apenas unos años antes se estuviesen administrando a los enfermos de los hospitales sevillanos. Evidente que esta circunstancia nos da idea de la rapidez con que las plantas medicinales indígenas fueron introducidas en el mercado europeo.

Pero, sin duda, el elixir indígena que más ampliamente se comercializó y se difundió en España fue el bálsamo. Este licor se extraía del Guaconax o Boní, planta que abundaba en la Española, especialmente en la región de Higüey ${ }^{39}$. La receta y sus virtudes las describió el tantas veces citado Fernández de Oviedo con gran lujo de detalles:

\footnotetext{
"Digo que hay ya muchos en esta isla que saben hacer este bálsamo, el cual, según algunos afirman, se hace de trozos pequeños de estos tales árboles, que, cocidos en agua, sale de ellos un licor como aceite, o más espeso, de color de arrope claro; y usan de él para las heridas frescas y cuchilladas o lanzadas, o cualquier otra herida reciente, porque inmediatamente restaña la sangre, y no se ha visto ni se sabe otra cosa medicinal que tan presto suelde y cierre la llaga..." 40 .
}

Efectivamente, parece ser que este licor tenía unas excelentes propiedades curativas que fueron ratificadas por médicos de ambos lados del océano. Concretamente, el licenciado Barreda, en 1529, se lamentó del daño que se hacía a la población de la isla concediendo el monopolio de su explotación, pues, tras haberse experimentado,

\footnotetext{
36 BENZONI (1989): Op. Cit., p. 148.

37 Ibidem, p. 206.

38 Real Cédula a los oficiales de Sevilla, Avila, 31 de julio de 1531. AGI, Indiferente General 1961, L. 2. Real Cédula a los oficiales de la Casa de la Contratación de Sevilla para que informasen de la cantidad de guayacán que había en las atarazanas de Sevilla, Avila, 31 de julio de 1531. AGI, Indiferente General 1961, L. 2, ff. 88v-89.

39 FERNANDEZ De OVIEDO (1992): Op. Cit., T. II, Lib. XI, Cap. IV, p. 19.

40 Ibidem, T. II, Lib. X, Cap. III, p. 11.
} 
se había demostrado su eficacia para "resteñir la sangre en las llagas frescas..." 41 . Igualmente, en España fue probado por varios médicos prestigiosos con similar resultado. Así, por ejemplo, en Sevilla fue suministrado experimentalmente a varios pacientes por el doctor Morales, quien al poco tiempo escribió a Carlos V explicándole la mejoría de todos ellos ${ }^{42}$. Poco después, en la villa de Cuellar, el doctor Juan de Vargas aplicó el bálsamo a ciertos enfermos también con el mismo éxito ${ }^{43}$.

A mediados de la década de los veinte, Antonio de Villasante ${ }^{44}$ pidió al Rey la confirmación del monopolio que sobre la explotación del bálsamo le había concedido el segundo Almirante Diego Colón ${ }^{45}$. Se trataba de una planta que, según explicó Villasante, se extendía por la Española, Cuba, San Juan, Tierra Firme "y quizá en la Nueva España". El había aprendido la preparación del licor de los indios tras más de treinta años de residencia en la Española casado con una mujer india y en continua "conversación con otros indios"46. Las propiedades curativas del bálsamo eran exaltadas en el memorial de Villasante como si se tratara de un elixir mágico, pues, según decía, no sólo cerraba rápidamente las heridas, sino que calmaba el dolor de estómago, curaba catarros, dolores de hígado, hinchazones, dolor de muelas, etc. ${ }^{47}$.

41 Relación del licenciado Barreda a Su Majestad, Santo Domingo, 26 de octubre de 1529. AGI, Patronato 174, R. 43. El licenciado Barreda era un médico de reconocido prestigio en la isla Española donde estaba afincado al menos desde 1517. MiŔa CABAllos (1994): Op. Cit., p. 183.

42 Real Cédula al Doctor Morales, Madrid, 5 de abril de 1530. AGI, Indiferente General 422, L. 14, ff. 68-69.

43 En esta ocasión Carlos V, para enterarse de una vez de las propiedades exactas del bálsamo, pidió a las autoridades de la villa que enviasen a la Corte a las personas que habían sanado con el bálsamo para, bajo juramento, interrogarlas. Real Cédula al alcalde mayor y a los alcaldes ordinarios de la villa de Cuellar, Segovia, 16 de octubre de 1532. AGI, Indiferente General 422, L. 15, ff. 197v-198.

44 En unos documentos aparece como Antonio de Villasante y en otros como Villasanta. Sin embargo, nosotros los hemos unificado todos con el primer apellido que es el más repetido. Este colono no se sabe cuando arribó a la Española aunque vivía ya en la isla durante el gobierno de fray Nicolás de Ovando. Al parecer estuvo identificado de manera más o menos tácita con el grupo de los colonistas, enfrentados durante años a los oficiales. Véase SCHÄFER, E. (1935): "Antonio de Villasante descubridor droguista en la Isla Española”, Investigación y Progreso, año IX. Madrid, (pp. 13-15), p. 13.

45 Según su relación se llamaba Bálsamo en castellano, en lengua de indios boní, en otras provincias Guacunae y en Tierra Firme canaguey. Relación de Antonio de Villasante a Su Majestad, Santo Domingo, S/F. AGI, Indiferente General 857 . Además de 300.000 maravedís perpetuos en la renta del bálsamo Colón le concedió 50.000 maravedís en la renta del ruibarbo y 50.000 maravedís en la renta de las demás drogas. Real Cédula a Antonio de Villasante, Granada, 9 de noviembre de 1526. AGI, Indiferente General 421, L. 11, ff. 292v-293v.

46 Real Cédula a Antonio de Villasante, vecino de Santo Domingo, Granada, 9 de noviembre de 1526. AGI, Indiferente General 421, L. 11, ff. 292v-293v.

47 Además en esta relación le habló de otras hierbas y árboles que los indígenas utilizaban médicamente y que eran muy útiles, como el "caquen", que aliviaba el dolor de cabeza, "turbi", "cahigua", "ruypontito", "haygua", "manzanillos de donde se coje la camonea y haoyno de donde los españoles sacan la trebentina". Relación de Antonio de Villasante a Su Majestad, S/F. AGI, Indiferente General 857. 
Incluso, - continúo citando a Villasante-, usado con reiteración "refresca mucho la complexión humana y no envejecen los hombres"48.

En 1528 la Corona fijó definitivamente los privilegios exactos con Villasante, estableciéndose la tercia parte de los beneficios no sólo del bálsamo sino de cualquier otra "droga" que quisiera comercializar, siempre que no excediese la renta de 8.000 ducados al año ${ }^{49}$. Igualmente se le concedieron otras muchas prerrogativas tales como la tenencia de la fortaleza de Santo Domingo cuando vacase, un regimiento en Santo Domingo, la posibilidad de establecer mayorazgo, un repartimiento de 150 indios en la Española y en Tierra Firme, la posibilidad de alquilar una casa en Santo Domingo y la exención del pago de almojarifazgo de las herramientas que hubiese de llevar para explotar el bálsamo ${ }^{50}$. Se trataba de unos privilegios excepcionales que muestran claramente el interés que puso la Corona en su explotación.

Sin embargo, como Villasante no disponía de capital para invertir en semejante empresa tuvo que recurrir al genovés Benito de Basinana, quien le dio el dinero a cambio nada menos que de una quinta parte a perpetuidad de sus ingresos netos ${ }^{51}$. En compañía con este empresario genovés comenzó a funcionar la empresa en 1529, obteniendo en un primer momento grandes resultados, pues en dicho año ya se habían enviado a la Casa de la Contratación de Sevilla cantidades importantes de bálsamo, que había sido distribuido a numerosos hospitales españoles ${ }^{52}$.

En 1530 se aplicó, aún experimentalmente, este fármaco en los siguientes hospitales: Cardenal de Toledo, Cardenal de Sevilla, Rey de Burgos, Santo Domingo de la Calzada, Santiago de Galicia, Hospital Real de Granada y en la enfermería del monasterio de Guadalupe ${ }^{53}$. Igualmente hubo médicos en estos años que lo aplicaron con resultados exitosos al parecer, según se desprende de las felicitaciones que Car-

48 Real Cédula a Antonio de Villasante, Granada, 9 de noviembre de 1526. AGI, Indiferente General 421, L. 11, ff. 292v-293v.

49 Asiento entre el Rey y Antonio de Villasante, Madrid, 4 de abril de 1528. AGI, Indiferente General 421, L. 13, ff. 85-86v. Villasante intentó comercializar sin éxito otras drogas, como la mirra, de la cual se decía que tenía muy buenas propiedades y que había sido utilizada durante siglos por los indígenas. Sabemos que, al menos en 1531, envió a Sevilla ciertas cantidades de este licor. Real Cédula a los oficiales de Sevilla, Ocaña, 4 de abril de 1531. AGI, Indiferente General 1961, L. 2, ff. 49-49v.

50 Ibidem. También Real Cédula a los oficiales de la isla Española, Madrid, 22 de abril de 1528. AGI, Indiferente General 421, L. 13, ff. 94v-95.

51 Real Cédula a Antonio de Villasante, Monzón, 5 de junio de 1528. AGI, Indiferente General 421, L. 13, ff. 191v-192.

52 Real Cédula a los oficiales de la Casa de la Contratación de Sevilla, Toledo, 24 de agosto de 1529. AGI, Indiferente General 1952, L. 1, ff. 2v-3.

53 Real Cédula a los visitadores del hospital del Cardenal de Toledo, del Cardenal de Sevilla, del Rey de Burgos, de Santo Domingo de la Calzada, de Santiago de Galicia y Real de Granada, Madrid, 5 de abril de 1530. AGI, Indiferente General 422, L. 14, ff. 72-72v. Real Cédula al prior y frailes del monasterio de Guadalupe, Madrid, 22 de diciembre de 1530. AGI, Indiferente General 1961, L. 2, ff. 16v-17. 
los $\mathrm{V}$ les remitió ${ }^{54}$. El éxito fue tal que el 4 de abril de 1531 se expidió una nueva Real Cédula para que se enviase una muestra del licor de bálsamo ya elaborado a la propia corte de Carlos V55.

En cuanto a cifras concretas, sabemos que hasta 1532 fueron enviadas a Sevilla por Villasante y Basinana al menos 29'5 arrobas de licor puro de bálsamo, cifra a la que habría que unir el que se introdujo ilegalmente que, a juzgar por las numerosas quejas, debió igualar al menos la mencionada cantidad ${ }^{56}$.

El negocio fue tan rentable en sus comienzos que hubo grandes dificultades para que los vecinos, no sólo de la Española sino de otras partes del Continente americano, respetasen el monopolio. El descontento de la población era considerable debido a que debían pagar dinero por un producto que abundaba en la isla y que creían necesario para la salud. Hubo problemas a nivel personal, incluso con el propio fray Bartolomé de las Casas, el cual fue acusado de mandar bálsamo a su hermana Catalina que se encontraba en México ${ }^{57}$. El cabildo de Santo Domingo también se opuso al monopolio de Villasante, impidiendo la recogida del tan preciado producto.

Muchos vecinos de la Española enviaban bálsamo "secretamente" a sus familiares españoles, e incluso los Bélzares, desde Venezuela, estaban consiguiendo grandes beneficios con este producto medicinal. Precisamente con estos últimos se generó un largo pleito con Villasante por el monopolio del preciado bálsamo, ya que, pese a la oposición de Villasante, esta compañía alemana consiguió, en 1537, licencia real para explotar el bálsamo en su demarcación de Venezuela ${ }^{58}$.

La fiebre del bálsamo llegó hasta tal extremo que en 1531 los encargados de distribuirlo en Sevilla, nombrados por Villasante, se quejaron de que se vendía mucho bálsamo falso, lo que redundaba, primero, en un perjuicio del fármaco - ya que se vendía adulterado- - y, segundo, en una reducción notable de las ventas ${ }^{59}$.

La Corona se vio obligada a tomar partido ordenando, en primer lugar, a los oficiales de la Española que impidiesen el envío de bálsamo de toda persona no autori-

54 Real Cédula al Doctor Morales, Madrid, 5 de abril de 1530. AGI, Indiferente General 422, L. 14 ff. 68-69. Real Cédula a las justicias de la villa de Cuellar, Segovia, 16 de octubre de 1532. AGI, Indiferente General 422, L. 15, ff. 197v-198.

55 SCHÄFER (1935): Op. Cit., p. 15.

56 Real Cédula a los oficiales de Sevilla, Madrid, 17 de noviembre de 1532. AGI, Indiferente General 1961, L. 2.

57 Real Cédula a los oficiales de la Casa de la Contratación para que averigüen si el bálsamo que mandó Bartolomé de Las Casas desde Puerto Plata lo envío antes de establecerse el asiento con Villasante, Madrid, 13 de diciembre de 1529. AGI, Indiferente General 1952, ff. 31-31v.

58 La licencia fue concedida por Real Cédula dada en Valladolid el 19 de enero de 1537. Hay documentación sobre este asunto en el Archivo General de Indias en las secciones de Justicia $11, \mathrm{~N}^{\circ} 7$, Contratación 5090, L. 1, f. 26 e Indiferente General 1206, № 3.

59 Real Cédula a los corregidores y justicias de los reinos de Castilla, Ocaña, 25 de enero de 1531. AGI, Indiferente General 422, L. 15, ff. 5v-6v. 
zada expresamente por Villasante ${ }^{60}$. Asimismo, en Sevilla ratificó la autorización que Benito de Basinana y Francisco Leardo tenían para distribuir, por tres años, el bálsamo en la ciudad ${ }^{61}$.

Además, para conseguir que se bajase el precio a 16 reales con el fin de que lo pudiese disfrutar "todo el mundo", se ordenó a los administradores de las alcabalas que no cobrasen el impuesto de la venta del bálsamo62. Igualmente, se mandó a todos los corregidores y justicias del reino que favoreciesen su comercio ${ }^{63}$, pidiendo al mismo tiempo que ningún médico difamase el fármaco sin antes experimentar con él64.

El negocio debió resultar rentable durante algunos años, pues, en 1531, se decía que Antonio de Villasante obtenía tan sólo en las cinco tiendas que tenía en Santo Domingo más de 100 pesos de oro anuales ${ }^{65}$. Sin embargo, parece ser que Villasante falleció en algún año de la década de los treinta, pues en estos años se le pierde totalmente el rastro, y ni sus sucesores ni sus socios continuaron con el negocio. Es posible que la Corona tras su muerte eliminara el monopolio, desapareciendo su tráfico comercial al menos como negocio.

A modo de resumen podemos decir que los conocimientos herborísticos de los indígenas de la Española, al igual que los de las demás Antillas Mayores, fueron bastante amplios. Sus curanderos o behiques tenían unos amplios conocimientos médicos en los que se sustentaba precisamente su prestigio. Igualmente ha quedado claro a lo largo de este trabajo que los indígenas intentaron ocultar esos conocimientos a los españoles para que las enfermedades los convencieran de abandonar esos territorios, constituyendo, sin duda, un elemento más de la resistencia pasiva mostrada frente al grupo hispano.

Igualmente ha quedado bien patente la fe que tuvieron algunos españoles en la medicina indígena y que los llevó a comercializar los fármacos en España. Durante

60 Real Cédula a los oficiales de la Española, Madrid, 5 de abril de 1530. AGI, Indiferente General 422, L. 14, ff. 69-70.

61 Real Cédula a Benito de Basinana y Francisco Leardo, Madrid, 5 de abril de 1530. AGI, Indiferente General 422, L. 14, ff. 61-63. Estos a su vez contaban con los servicios del cirujano Juan de Peralta el cual se encargaba de "ir por toda el Andalucía y otras partes a curar, vender y distribuir el bálsamo". Real Cédula a los oficiales de la Casa de la Contratación, Madrid, 22 de diciembre de 1530. AGI, Indiferente General 1961, L. 2, ff. 16-16v.

62 Real Cédula a los recaudadores de las alcabalas, Madrid, 5 de abril de 1530. AGI, Indiferente General 422, L. 14, ff. 65-66.

63 -Real Cédula a los corregidores y justicias del reino, Madrid, 5 de abril de 1530. AGI, Indiferente General 422, L. 14, ff. 64-65.

64 Real Cédula a los oficiales de la Casa de la Contratación, Madrid, 5 de abril de 1530. AGI, Indiferente General 422, L. 14, ff. 57v-58.

65 Carta de Diego Caballero a Su Majestad, Santo Domingo, 18 de marzo de 1531. MARTE, R. (1981): Santo Domingo en los manuscritos de Juan Bautista Muñoz. Santo Domingo, Fundación García Arévalo, p. 353. 
algunos años hubo personas que se lucraron con el comercio de estos fármacos, especialmente Villasante, que explotó durante un breve periodo de tiempo su monopolio sobre el bálsamo. Finalmente llama la atención el hecho de que, en 1530, cuando la realidad americana se percibía aún tan difusa en el Reino de Castilla, se administrasen en muchos de sus hospitales las medicinas que durante siglos habían consumido los desdichados indios americanos. 